\title{
COMMENTARY
}

\section{Teaching Intellectual Humility is Essential in Preparing Collaborative Future Pharmacists}

\author{
Ike de la Peña, PhD, ${ }^{\text {a Jessa Koch, PharmD }}{ }^{\text {a,b }}$ \\ ${ }^{a}$ Loma Linda University, School of Pharmacy, Loma Linda, California \\ ${ }^{\mathrm{b}}$ Loma Linda University, School of Medicine, Loma Linda, California
}

Corresponding Author: Ike de la Peña, Loma Linda University, School of Pharmacy, 11175 Campus Street, Loma Linda, CA 92350. Tel: 909-651-5995. Email: idelapena@1lu.edu

Submitted October 28, 2020; accepted February 23, 2021; ePublished February 2021

Interprofessional teams contribute significantly to patient care and safety. However, barriers to effective interdisciplinary collaboration have been identified, such as power dynamics and mistrust among team members, contrasting ideologies, interests and levels of engagement of clinicians, and disciplinary territoriality, which could negatively impact patient care. Teaching current health professional students behaviors and personal values that promote collaboration is critical in equipping them to function effectively in an interdisciplinary care setting. In this commentary, we put forward the idea that teaching intellectual humility is important in preparing collaborative future pharmacists. The core dimensions of intellectual humility, namely, open-mindedness, intellectual modesty, engagement and corrigibility are important behaviors that could address the above-mentioned barriers, and promote successful interdisciplinary collaboration. Furthermore, we suggest strategies through which student pharmacists could be taught intellectual humility, mainly within the interprofessional education setting.

Keywords: intellectual humility, interprofessional collaboration, interprofessional education

\section{INTRODUCTION}

As defined by the Interprofessional Education Collaborative (IPEC), interprofessional team-based care is "care delivered by intentionally created, usually relatively small work groups in health care, who are recognized by others as well as by themselves as having a collective identity and shared responsibility for a patient or group of patients." ${ }^{1}$ The important contributions of interprofessional collaboration in improving patient care and safety have been recognized since the 1970 s. $^{2}$ Despite these encouraging outcomes, several barriers to interdisciplinary practice have been identified. Some of the problems at the individual level include power dynamics and mistrust among clinicians, differences in ideologies, interests and levels of engagement of participants, and disciplinary territoriality, which could lead to conflict and negatively affect the quality of patient care. . $^{3,4}$

Several institutions have proposed the characteristics or principles of effective interdisciplinary teams. The IPEC panel, in particular, identified four core competency domains, namely, values and ethics, roles or responsibilities, communication, and team and teamwork (Table 1). ${ }^{1}$ It also defined the sub-competencies in each domain. Nevertheless, a major challenge facing health professional education is implementing curricular interventions that could enhance students' competence in interprofessional collaborative practice. ${ }^{5}$ Of note, a work group drawn from the Institute of Medicine's Best Practices Innovation Collaborative identified collaboration-promoting behaviors and personal values, which they recommended to be taught to current health professional students. ${ }^{6}$ These values, which supplement the core competencies proposed by IPEC, were honesty, discipline, creativity, curiosity and humility. Humility, in particular, warrants team members to "recognize differences in training" but not believe that "there is a type of training or perspective that is uniformly superior to the training of others." It also calls for team members to "recognize that they are human and will make mistakes." Humility, in this context, refers to "general" humility, which is "recognizing one's fallibility to make errors." In the succeeding sections, we describe a virtue called "intellectual humility", which is different from general humility, and discuss how its implementation could promote interprofessional collaboration. Next, we suggest strategies that pharmacy educators could use to teach student pharmacists intellectual humility, mainly within the interprofessional education (IPE) framework.

\section{What is intellectual humility?}

Intellectual humility is fundamentally a cognitive phenomenon, which involves "recognizing that one's beliefs and opinions might be incorrect." "Showing intellectual humility, however, does not mean being uncertain about one's 
beliefs or viewpoints. Contrastingly, it demonstrates awareness that one's ideas might be flawed, and acknowledgment that one may not have sufficient information and expertise to understand and evaluate aspects of the evidence. ${ }^{8}$

Nevertheless, an associated feature of intellectual humility is engagement, i.e., engaging in and enjoying cognitive activities. ${ }^{8}$ While fundamentally an assessment of one's own beliefs and knowledge, intellectual humility also manifests through openness to other peoples' ideas and viewpoints. ${ }^{8}$ Moreover, it is characterized by flexibility and lack of conceit with regard to one's beliefs and opinions ${ }^{8}{ }^{8}$ As Krumrei-Mancuso and Rouse put it, intellectual humility is a "healthy independence between intellect and ego." ${ }^{9}$ Furthermore, intellectual humility is associated with low defensiveness, or showing emotional resilience when one's beliefs are questioned or challenged..$^{8,10}$

Alfano and colleagues, who recently developed and validated a tool to measure intellectual humility, proposed four core dimensions of the behavior, namely, open-mindedness, intellectual modesty, corrigibility and engagement (Table 1). ${ }^{10}$ Recent research have identified significant implications and benefits of applying intellectual humility in various domains, for instance, sociopolitics, religion, education, business and leadership. ${ }^{7,11,12}$ Based on the above conceptualization of intellectual humility, we propose that the trait is also beneficial in promoting interdisciplinary collaboration. As discussed below, the core dimensions of intellectual humility may facilitate effective collaborations among members of a health care team.

\section{Facilitating role of intellectual humility in interprofessional collaboration}

Mapping the core dimensions of intellectual humility to the corresponding core competency domains proposed by IPEC brings to light a potential facilitating role of intellectual humility in interdisciplinary collaboration (Table 1). Within the interprofessional setting, each team member yields unique knowledge, experiences, and skills. Cultivating openmindedness could result in team members respecting the individual contributions and expertise of other health professionals. Disagreements on the course of care is inevitable due to the variation in training and experience of team members. Open-mindedness could promote willingness to listen to and learn from a variety of viewpoints, and thus, prevent or resolve disagreements.

Training on intellectual modesty could encourage team members to recognize their limitations, and thus, prevent them from exuding superiority and overconfidence in their knowledge. It could also keep them "grounded" (to not think about their "status" in the team), and thus, promote willingness to work with others. Corrigibility could enhance interprofessional interactions, with team members responding respectfully to feedback from fellow health care providers. It could also eliminate defensiveness when one's clinical decisions are challenged, and openness to revising one's clinical decisions when warranted. Finally, engagement could result in health professionals continuously learning from each other; to be actively involved in resolving issues that may arise within the team, and to seek opportunities for lifelong professional and interprofessional development. Team members who demonstrate intellectual humility would listen to and learn from one another to develop the best clinical plan based upon the evidence provided. Eventually, this will break down the silo mentality, positively influence the dynamics of the interprofessional team, and lead to the ultimate benefitthe provision of better care for patients.

\section{Strategies to teach intellectual humility to student pharmacists}

In view of the potential collaboration-promoting role of intellectual humility, teaching this trait to student pharmacists is critical in preparing them for interdisciplinary practice. Trainings in intellectual humility could be offered through an elective course within the pharmacy curriculum. The University of Edinburgh, for example, has recently offered an online course on the science and applications of intellectual humility. ${ }^{13}$ However, we believe that the IPE introduced throughout the core curriculum is the most appropriate venue for teaching intellectual humility. Within this setting, students from the different health professional tracks could be informed about the benefits of intellectual humility in interprofessional collaboration. Prior to IPE sessions, all students could take assessments (eg, validated surveys) to determine the degree of their intellectual humility. If need be, students could be taught the core dimensions of the behavior and specific strategies to apply them during the IPE sessions. Furthermore, the students' biases or stereotypes of their own profession and that of others could also be addressed, in view of health care students' (including student pharmacists) inclination towards "in group favoritism", or the tendency to favor members of one's own group over those in other groups. ${ }^{14,15}$ Such in-group bias, which is oftentimes driven by an effort to seek higher self-esteem, ${ }^{15}$ does not conform to the principles of intellectual humility, and could potentially hinder interprofessional collaboration.

During the IPE sessions, students could be given comprehensive patient cases that would harness their individual skill sets and expertise. These cases could be designed with the addition of simulation or standardized patient involvement. The case development process should involve all faculty members representing the trainees' fields of study. Case problems must be crafted such that their completion is contingent upon the entire team communicating effectively, showing openness to different ideas, accepting one another's limitations, and responding respectfully to feedback and 
alternative ideas. Thus, students would be evaluated not only on successfully completing the patient cases, but also with regard to their application of intellectual humility to solve the case problems.

Teaching intellectual humility could also be implemented as students gain experiences through the introductory and advanced pharmacy practice experience (IPPE/APPE) programs. Pharmacy preceptors could intentionally instruct students on intellectual humility by referring them to the core dimensions of the behavior and their application in an interprofessional care setting. As mentioned above, encouraging student pharmacists to be open to ideas, to admit that they are wrong, to be engaged, and respond with resilience to feedback, will promote adoption of intellectual humility as students complete their IPPEs/APPEs. Incorporation of such behaviors would also serve as a model for other team members and learners (see Role modeling intellectual humility). Preceptors can also evaluate students' application of intellectual humility and instruct them on strategies to increase intellectual humility as they move towards a more autonomous role.

In order to evaluate effectiveness of intellectual humility trainings, self-assessments through reflective writing could be employed, which could also serve as a tool to reinforce teaching and for students to document their commitment toward fostering intellectual humility. Reflective writing could be structured to allow students to articulate and analyze the factors that promoted or hindered meaningful interactions with others during the IPE sessions and experiential learning. ${ }^{16}$ Through reflective writing, students could be asked to ponder on the instances wherein the application of intellectual humility was crucial, and contemplate strategies to address the barriers that prevented them or others from demonstrating this trait.

Research on the effectiveness of intellectual humility trainings within IPE, IPPE/APPE frameworks are crucial to establish the above-proposed collaboration-promoting role of intellectual humility. Such work will also determine whether IPE, IPPE/APPEs settings are the ideal venues for providing such training. Furthermore, follow up studies should also be conducted to determine whether students trained in intellectual humility really work better with others in a multidisciplinary team.

Although it might be challenging to teach intellectual humility given the contemporary society's incentivization of arrogance and assertiveness, ${ }^{17}$ pharmacy educators can increase student's adoption of intellectual humility by informing them of the personal benefits of being intellectually humble. Intellectual humility has been associated with better learning, and curiosity, which is a desired academic and professional outcome. ${ }^{7}$ In the context of diversity, equity, and inclusion, intellectual humility could help foster respect and openness to the diverse backgrounds and lived experiences of others, and motivate individuals to work toward equity and inclusion both in the professional as well as personal contexts.

\section{Role modeling intellectual humility}

"We must acknowledge ... that the most important, indeed the only, thing we have to offer our students is ourselves. Everything else they can read in a book."

In the above statement, the influential educator, Dr. D.C. Tosteson, emphasizes the significance of role modeling in medical education. ${ }^{18}$ Pharmacy educators and preceptors must embody intellectual humility in order for them to become effective trainers of this trait to student pharmacists. Intellectual humility is demonstrated when one admits that he/she does not know the answer to a question posed by a student or a colleague. This act does not make one appear unintelligent or indecisive. It does not compromise one's integrity; rather, it sets an example for learners to be honest as well about the gaps in their knowledge, which could enable teachers to address them more effectively. With the current expansion of knowledge and technology, and the rate by which new ideas are introduced, it is just impossible to know all information. Furthermore, narrations of personal stories and experiences ${ }^{19}$ that demonstrate intellectual humility are also effective ways to inculcate this virtue to student pharmacists.

Another way to model intellectual humility is by becoming more open to overall collaborative education, given that one barrier to the implementation of IPE, is the preference of some educators to work or teach within their established silos. ${ }^{20}$ Because intellectual humility leads to openness to new ideas and epistemic curiosity (the desire to obtain new knowledge), embracing it could also increase one's openness to explore the essence and value of collaboration across new disciplines.

Consciously modelling positive behaviors can transform health professions education. ${ }^{18}$ Educators and preceptors need to be explicit and intentional about role modeling intellectual humility in order for this strategy to work. ${ }^{18}$ Showing intellectual humility at all times may be difficult to achieve. However, educators and preceptors can strive to become consistently good models of this trait to their students.

\section{CONCLUSION}


Intellectual humility is an important virtue that aligns with the principles of effective interdisciplinary collaboration. Training in intellectual humility is critical in preparing professional and collegial future pharmacists, who will strive to learn more about themselves and the world around them, and function collaboratively with others to provide the best care for patients.

\section{REFERENCES}

1. Interprofessional Education Collaborative Expert Panel. (2016). Core competencies for interprofessional collaborative practice: 2016 update. Washington, D.C.: Interprofessional Education Collaborative. https://www.tamhsc.edu/ipe/research/ipec-2016-core-competencies.pdf. Accessed February 17, 2021.

2. Hammick M, Hoffman SJ, Highes L et al. Executive Summary. In: Diana Hopkins. Framework for action on interprofessional education and collaborative practice geneva world health organization. 2010. Geneva, Switzerland: World Health Organization;2010. https://www.who.int/hrh/resources/framework_action/en/. Accessed February 17, 2021.

3. McDonald J, Jayasuriya R, Harris MF. The influence of power dynamics and trust on multidisciplinary collaboration: a qualitative case study of type 2 diabetes mellitus. BMC Health Serv Res. 2012;12:63. doi:10.1186/1472-6963-12-63

4. O'Reilly P, Lee SH, O'Sullivan M, Cullen W, Kennedy C, MacFarlane A. Assessing the facilitators and barriers of interdisciplinary team working in primary care using normalisation process theory: An integrative review. PloS one. 2017;12(5):e0177026-e0177026. doi:10.1371/journal.pone.0177026

5. McLaughlin JE, Bush AA, Rodgers PT, Scott MA, Zomorodi M, Roth MT. Characteristics of high performing interprofessional teams involving student pharmacists. Am J Pharm Educ. 2019:ajpe7095. doi:10.5688/ajpe7095

6. Mitchell, P, M Wyna, R Golden, B McNellis, S Okun, CE Webb, V Rohrbach and I Von Kohorn. Core principles and values of effective team based health care. discussion paper, Institute of Medicine, Washington, DC. 2012

7. Krumrei-Mancuso EJ, Haggard MC, LaBouff JP, Rowatt WC. Links between intellectual humility and acquiring knowledge. J Posit Psychol. 2020;15(2):155-170. doi:10.1080/17439760.2019.1579359

8. Leary MR, Diebels KJ, Davisson EK, et al. Cognitive and interpersonal features of intellectual humility. Pers Soc Psychol Bull. 2017;43(6):793-813. doi:10.1177/0146167217697695

9. Krumrei-Mancuso EJ, Rouse SV. The development and validation of the comprehensive intellectual humility scale. J Pers Assess. 2016;98(2):209-221. doi:10.1080/00223891.2015.1068174

10. Alfano M, Iurino K, Stey P, et al. Development and validation of a multi-dimensional measure of intellectual humility. PloS one. 2017;12(8):e0182950. doi:10.1371/journal.pone.0182950

11. Hook JN, Farrell JE, Johnson KA, Van Tongeren DR, Davis DE, Aten JD. Intellectual humility and religious tolerance. J Posit Psychol. 2017;12(1):29-35. doi:10.1080/17439760.2016.1167937

12. Krumrei-Mancuso EJ, Newman B. Intellectual humility in the sociopolitical domain. Self Identity. 2020;19(8):989-1016. doi:10.1080/15298868.2020.1714711

13. Intellectual humility: practice. Coursera website. https://www.coursera.org/learn/intellectual-humilitypractice\#syllabus. Accessed February 17, 2021.

14. Thurston MM, Chesson MM, Harris EC, Ryan GJ. Professional stereotypes of interprofessional education naive pharmacy and nursing students. Am J Pharm Educ. 2017;81(5):84. doi:10.5688/ajpe81584

15. Everett JAC, Faber NS, Crockett M. Preferences and beliefs in ingroup favoritism. Review. Front Behav Neurosci. 2015;9(15)doi:10.3389/fnbeh.2015.00015

16. Burkhardt C, Crowl A, Ramirez M, Long B, Shrader S. A reflective assignment assessing pharmacy students' interprofessional collaborative practice exposure during introductory pharmacy practice experiences. Am J Pharm Educ. 2019;83(6):6830. doi:10.5688/ajpe6830

17. Wu J, Lowenstein E. Balancing confidence and humility in the diagnostic process. Diagnosis (Berlin, Germany). 2020;7(1):11-15. doi:10.1515/dx-2019-0037

18. Cruess SR, Cruess RL, Steinert Y. Role modelling--making the most of a powerful teaching strategy. BMJ (Clin Research Ed). 2008;336(7646):718-721. doi:10.1136/bmj.39503.757847.BE

19. Brazeau GA. Share all your stories. Am J Pharm Educ. 2018;82(10):7434. doi:10.5688/ajpe7434

20. Burgess A, van Diggele C, Matar E. Interprofessional team-based learning: building social capital. J Med Educ Curric Dev. 2020;7:2382120520941820. doi:10.1177/2382120520941820 
Table 1. Dimensions of intellectual humility Mapped to Core Competency Domains Proposed by the Interprofessional Education Collaborative

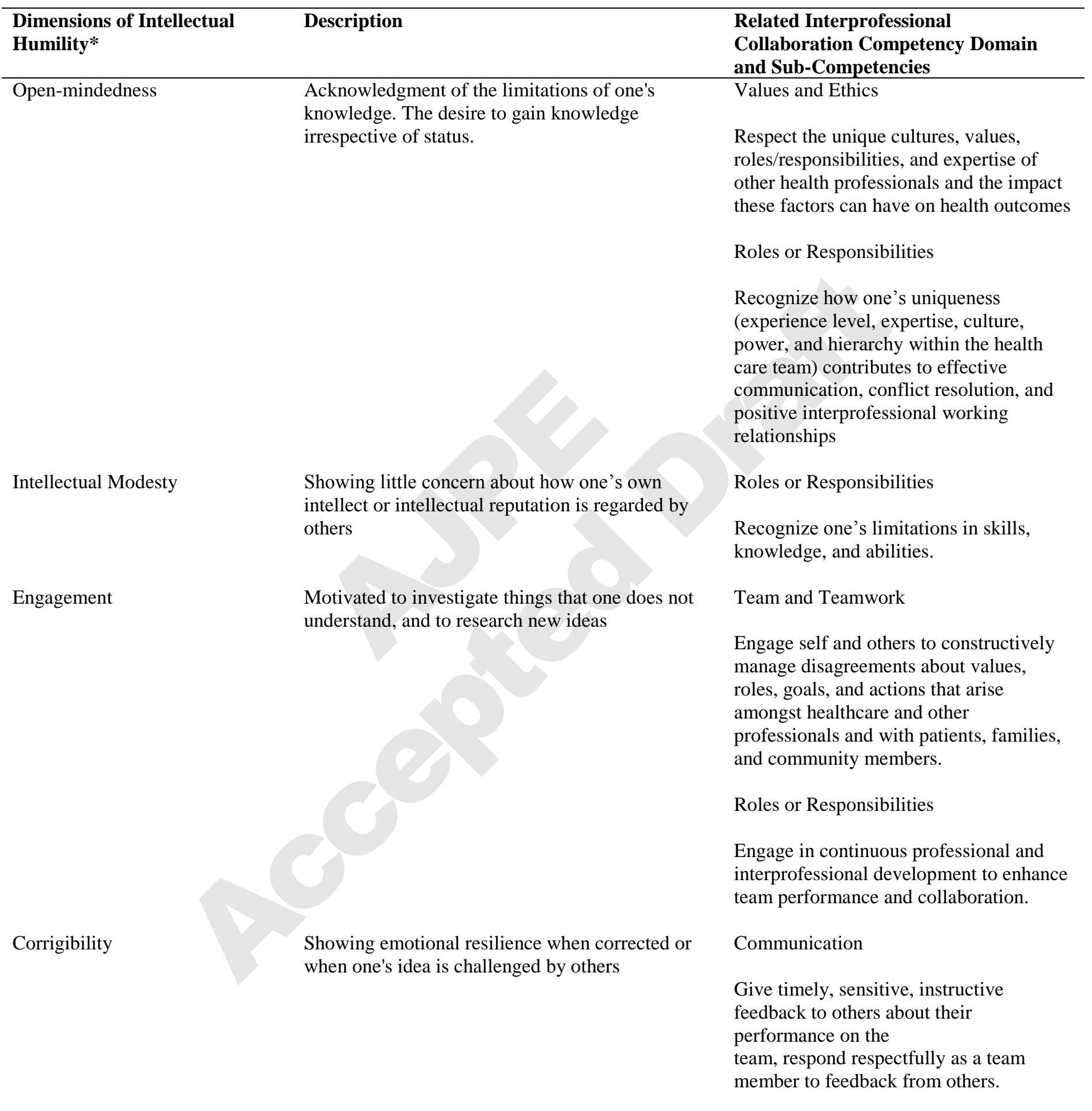

\footnotetext{
*The four core dimensions of intellectual humility according to Alfano et al.
} 